\title{
Finite element simulation of cutting HT250 process by self-prepared Si3N4 ceramic insert in different cutting speed
}

\author{
Bo Wang ${ }^{1, a}$, Jia Li ${ }^{2, b}$ and Jian-Tong Liu ${ }^{3, c}$ \\ 1.Zhuhai College of Jilin University, Zhuhai, 519041, China \\ a.wangbo00019@163.com, b.1164170422@qq.com,c.45188480@qq.com
}

Keywords: Finite element simulation; Si3N4 insert; Cutting performance; different cutting speed

\begin{abstract}
The simulation models were created based on the material properties of the self-prepared Si3N4 insert and HT250 workpiece. Using these models, the simulation results of cutting force, temperature and tool stress were availably obtained in different cutting speed. It was concluded by these results that the cutting properties of Si3N4 ceramic insert were optimum in $V_{c}=250$ or $300 \mathrm{~m} / \mathrm{min}$, due to low cutting force, low tool temperature, low stress-effective. It was also predicted the tool wear appeared at tool nose firstly.
\end{abstract}

\section{Introduction}

Si3N4 ceramics is one of the most important cutting tools materials, due to its good mechanical properties at high temperatures, superior thermal shock resistance, and wear and corrosion resistance. Before applied as cutting tools, the properties of developed Si3N4 ceramics must be test. The traditional cutting test method, adopted to confirm the cutting performance and optimize the process parameters, is difficult to get accurate and stable results. However, the finite element simulation could achieve the required accuracy and the highly reliability, avoid a large number of actual cutting experiments, and save time, manpower and material resources [1,2,3,4]. This method could acquire the data access to the real cutting experiment and the intuitive simulation image, predict the cutting properties of tool and optimize tool geometric parameters and cutting technology parameters.

\section{Preparing Si3N4 ceramic insert [5]}

The raw materials used in this study were consisted of $\alpha$-Si3N4 powder, La2O3, Yb2O3 and MgO. The starting powder mixtures were ball milled for $24 \mathrm{~h}$ in ethanol using Si3N4 balls. After drying, the powder was gently grounded and passed through a 100 mesh sieve. The mixed powder was performed on graphite die with specific tolerance between graphite punch and die. The Si3N4 sample was prepared by Hot Pressing Sintering at $1800^{\circ} \mathrm{C}$. Finally, the sample was made into Si3N4 inserts. The material properties of Si3N4 inserts were shown in table 1.

Table 1 Properties of Si3N4 ceramic insert.

\begin{tabular}{ccccccc}
\hline $\begin{array}{c}\text { Bending } \\
\text { strength } \\
(\mathrm{MPa})\end{array}$ & $\begin{array}{c}\text { HV hardness } \\
(\mathrm{GPa})\end{array}$ & $\begin{array}{c}\text { Fracture } \\
\text { toughness } \\
\left(\mathrm{MPa} \cdot \mathrm{m}^{1 / 2}\right)\end{array}$ & $\begin{array}{c}\text { Poisson's } \\
\text { ratio }\end{array}$ & $\begin{array}{c}\text { Yong's } \\
\text { modulus } \\
10^{3} \mathrm{MPa}\end{array}$ & $\begin{array}{c}\text { Heat } \\
\text { conductivity } \\
(\mathrm{W} /(\mathrm{m} \cdot \mathrm{K}))\end{array}$ & $\begin{array}{c}\text { Heat capacity } \\
(\mathrm{J} /(\mathrm{kg} \cdot \mathrm{K}))\end{array}$ \\
\hline 905 & 14.3 & 9.02 & 0.25 & 310 & 31 & 550 \\
\hline
\end{tabular}




\section{Finite element modeling}

The numerical approach in this paper was the Lagrangian formulation, which has been used to investigate the effect of machining parameters on residual stresses distribution. The Lagrangian formulation effectively analyzed the effect of cutting speed $[6,7,8]$.

\section{Geometries and mesh generation}

The geometric models of Si3N4 insert and HT250 workpiece were created in Deform software. Then, the workpiece and insert were meshed with, respectively, 61351 and 26994 isoparametric quadrilateral elements [9]. In order to improve the accuracy of analysis, the geometry meshes of tool nose were generated with element size ratio of 6 . The geometric models and mesh generation of Si3N4 insert and HT250 workpiece were respectively shown in a and b of Fig.1.

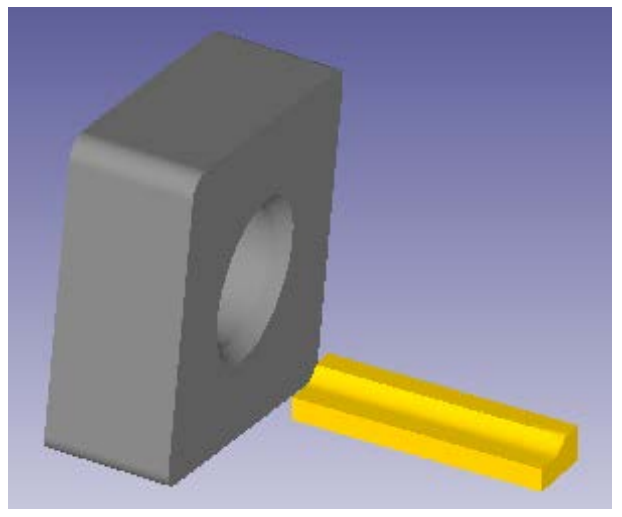

(a) Geometric models

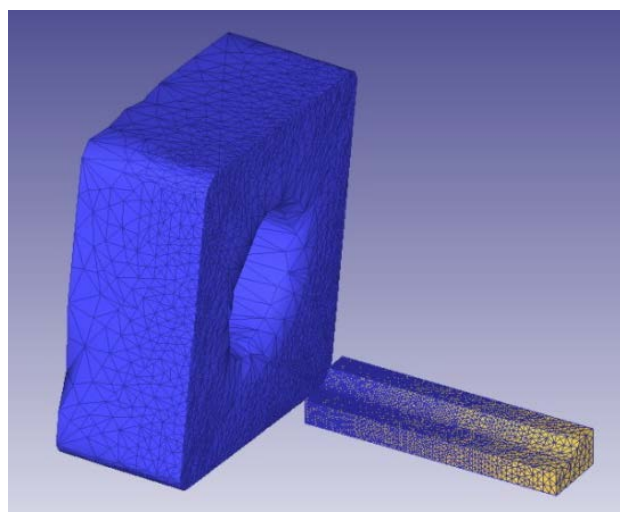

(b) Mesh generation

Fig.1 Geometries and mesh generation

\section{Material behavior modeling}

(1) Workpiece material behavior modeling

The constitutive law proposed by Johnson and Cook [10] provides a good description of material behavior subjected to large strains, high strain-rates and thermal softening [11]. The Johnson-Cook modeling, available in Deform software, was used in the simulation process. The law was described by Eq.1. The workpiece material used in this study was the grey iron HT250. The elastic and thermos-mechanical properties of HT250 were shown in Table2.

$$
\bar{\sigma}=\left[A+B(\bar{\varepsilon})^{n}\left[1+C \ln \left(\frac{\dot{\bar{\varepsilon}}}{\overline{\bar{\varepsilon}_{0}}}\right)\right]\left[1-\left(\frac{T-T_{\text {room }}}{T_{\text {melt }}-T_{\text {room }}}\right)^{m}\right]\right.
$$

In Eq.1, $\sigma$ is the material flow stress, $\bar{\varepsilon}$ is the equivalent plastic strain, $\dot{\overline{\varepsilon_{0}}}$ is the reference plastic strain rate, $\dot{\bar{\varepsilon}}$ is the plastic strain rate, $T_{\text {room }}$ and $T_{\text {melt }}$ are respectively the room and the melting temperatures. The coefficients (A, B C, $\mathrm{n}$ and $\mathrm{m}$ ), listed in Table 3, are obtained from tensile curves using a fitting program [12]. 
Table 2 Elastic and thermal properties parameters of HT250

\begin{tabular}{ccccc}
\hline $\begin{array}{c}\text { Density } \\
\left(\mathrm{Kg} / \mathrm{m}^{3}\right)\end{array}$ & Poisson's ratio & $\begin{array}{c}\text { Yong's modulus } \\
10^{3} \mathrm{MPa}\end{array}$ & $\begin{array}{c}\text { Heat conductivity } \\
(\mathrm{W} /(\mathrm{m} \cdot \mathrm{K}))\end{array}$ & \multicolumn{2}{c}{ Thermal expansion } \\
\hline 7190 & 0.26 & 126 & $100^{\circ} \mathrm{C} 49.1$ & $\left.-100 \sim 20^{\circ} \mathrm{C} /{ }^{\circ} \mathrm{C}\right)$ \\
& & & $200^{\circ} \mathrm{C} 48.1$ & $20 \sim 200^{\circ} \mathrm{C} 11.0$ \\
& & $300^{\circ} \mathrm{C} 47.1$ & $200 \sim 400^{\circ} \mathrm{C} \quad 12.5$ \\
\end{tabular}

Table 3 HT250 material constants for J-C model:

\begin{tabular}{ccccccccc}
\hline $\mathrm{A}$ & $\mathrm{B}$ & $\mathrm{C}$ & $\mathrm{n}$ & $\mathrm{m}$ & $T_{\text {room }}$ & $T_{\text {melt }}$ & $\dot{\overline{\varepsilon_{0}}}$ & $\dot{\bar{\varepsilon}}$ \\
\hline 573 & 380 & 0.034 & 0.17 & 0.12 & 20 & 1250 & 1 & 1 \\
\hline
\end{tabular}

(2) Insert material behavior modeling

In materials database of Deform software, the material behavior model of $\mathrm{Al} 2 \mathrm{O} 3$ ceramic is defined by the Power Law [9], shown as Eq.2. In this study, Si3N4 ceramic was also defined by the Power law.

$$
\bar{\sigma}=c \times \bar{\varepsilon}^{n} \times \dot{\bar{\varepsilon}}^{m}+y
$$

In Eq.2, $\bar{\sigma}$ is Flow stress, $\bar{\varepsilon}$ is effective plastic strain, $\dot{\bar{\varepsilon}}$ is effective strain rate, c is material constant, $\mathrm{n}$ is strain exponent, $\mathrm{m}$ is Strain rate exponent, $\mathrm{y}$ is initial yield value. The Si3N4 ceramic properties are shown in Table 1.

\section{Contact and friction modeling}

Zorev [13] proposed the most realistic description of normal and frictional stress distribution at tool-chip interface, as shown in Fig.2. The author assumed that the tool-chip interface was subdivided into two zones [14]: sticking zone and sliding zone. In the sticking zone $\left(\mathrm{x} \leq l_{p}\right)$, the shear stress reach the saturation values $\tau_{\max }$. In the sliding zone $\left(l_{p} \leq \mathrm{x} \leq l_{c}\right)$, the frictional shear stress does not reach the saturation values $\tau_{\max }$. The frictional stress can be expressed as Eq3. In Eq.3, $\mu=0.45$ [15].

$$
\left\{\begin{array}{l}
\tau_{f}=\mu \times \sigma_{n} \quad \text { if } \mu \times \sigma_{n}<\tau_{\max } \text { (Sliding) } \\
\tau_{f}=\tau_{\max } \quad \text { if } \mu \times \sigma_{n} \geq \tau_{\max } \text { (Sticking) }
\end{array}\right.
$$

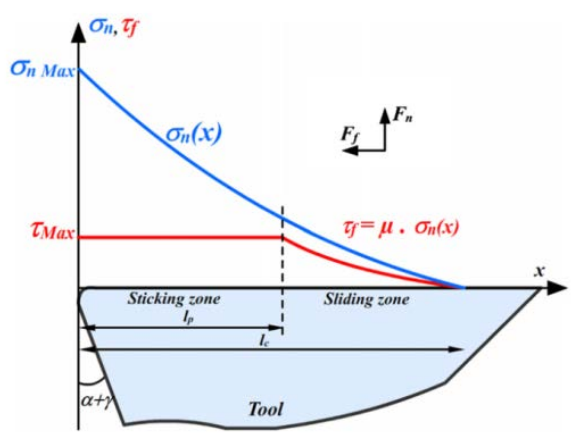

Fig.2 Normal and frictional stress distributions at tool-chip interface [16]. 


\section{Finite element simulation and discussions}

After finite element modeling, the simulation tests were carried out in different cutting condition. The cutting parameters were listed in Table 4. The number of simulation steps parameter was defined by 500. Fig. 4 was the images of simulation processes. Cutting force, temperature field and stress field were analyzed as the main analysis parameters for confirming cutting performance during the simulation process.

Table 4 Cutting parameters

\begin{tabular}{ccc}
\hline Cutting speed $\mathrm{V}_{c}(\mathrm{~m} / \mathrm{min})$ & Depth of cut $a_{p}(\mathrm{~mm})$ & Feed rate $\mathrm{f}(\mathrm{mm} / \mathrm{rev})$ \\
\hline $200 / 250 / 300 / 350$ & 0.5 & 0.15 \\
\hline
\end{tabular}

\section{Cutting force analysis}

Cutting force is the main analysis parameter for researching the cutting process, which related to cutting heat generation, tool wear, machining accuracy. Fig. 3 showed the simulation results of the main cutting force, which gradually rise from zero up to maximum, stabilized within the particular range finally. The max main cutting forces in different cutting speeds $\left(\mathrm{V}_{c}=200,250,300,350 \mathrm{~m} / \mathrm{min}\right)$ were respectively $573 \mathrm{~N}, 528 \mathrm{~N}, 529 \mathrm{~N}, 553 \mathrm{~N}$. The Relationship between the main cutting force and cutting speed was shown in Fig.4. The main cutting force reached to the max in $V_{c}=200 \mathrm{~m} / \mathrm{min}$, while the main cutting force was the minimum in $\mathrm{V}_{c}=250$ or $300 \mathrm{~m} / \mathrm{min}$.
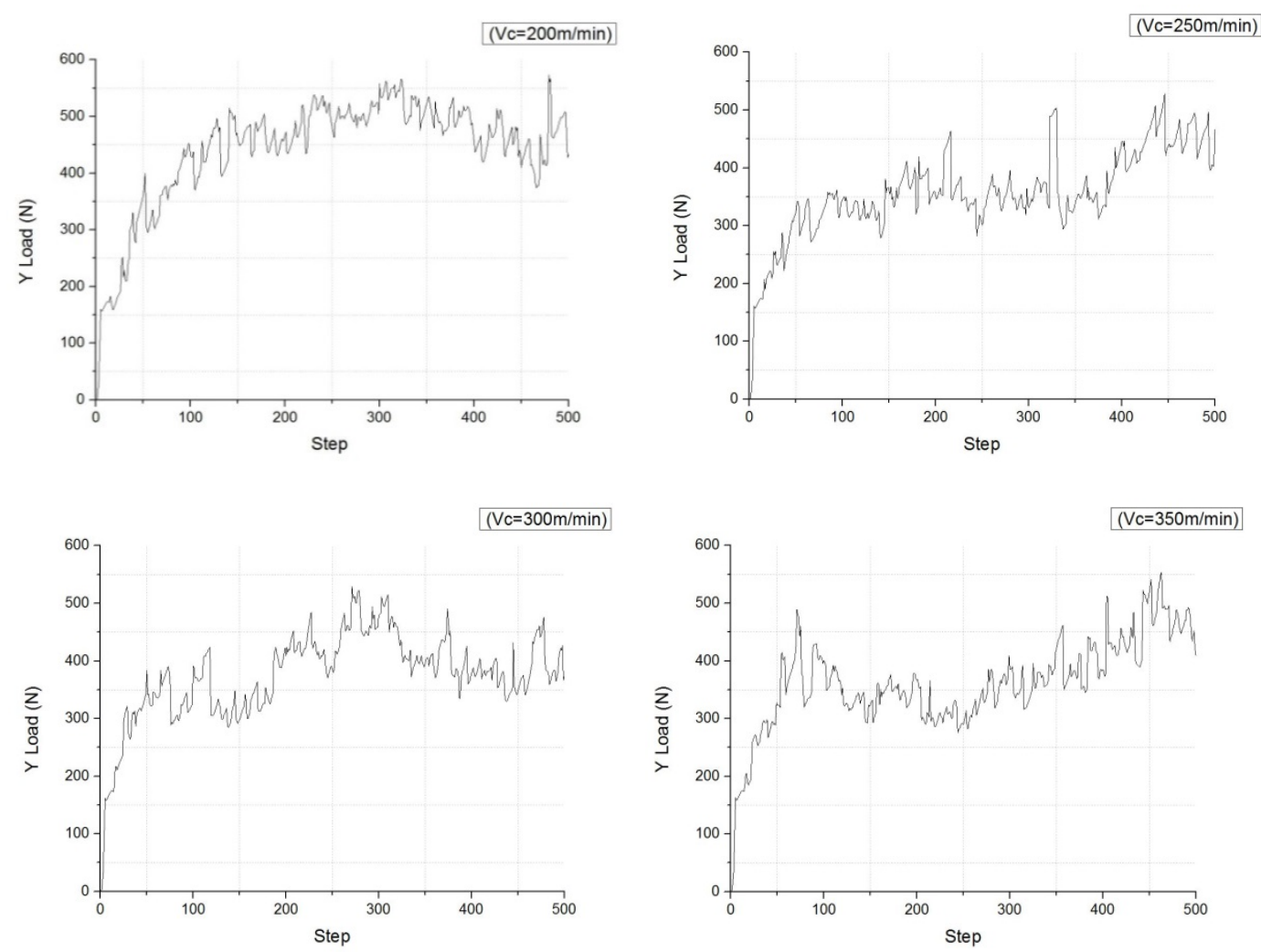

Fig.3 Results of the main cutting force. 


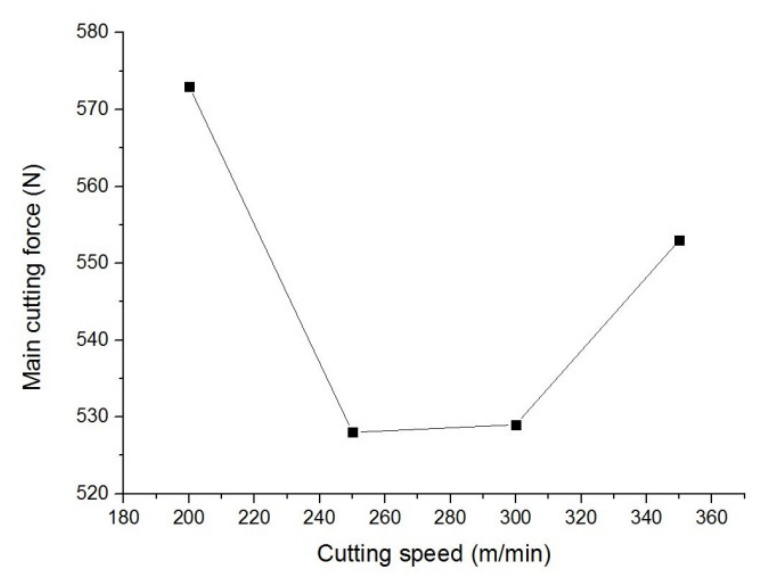

Fig.4 Relationship between cutting force and cutting speed.

\section{Temperature field analysis}

Heat generation is mainly caused by metal deformation in cutting process. The distribution of temperature fields in different cutting speed were shown in Fig.5. The temperature of Si3N4 insert was only more than $20^{\circ} \mathrm{C}$, while the temperature of chip was beyond $900^{\circ} \mathrm{C}$. It mainly depended on the low thermal conductivity of Si3N4 ceramic, which ensured effective cutting tool life. Fig.6 showed the relationship between tool temperature and cutting speed. The tool temperature was highest in $V_{c}=200 \mathrm{~m} / \mathrm{min}$. When cutting speed was beyond $250 \mathrm{~m} / \mathrm{min}$, the tool temperature was no longer changing. It was caused that the more heat generated by deformation were taken away by chip with cutting speed increase.
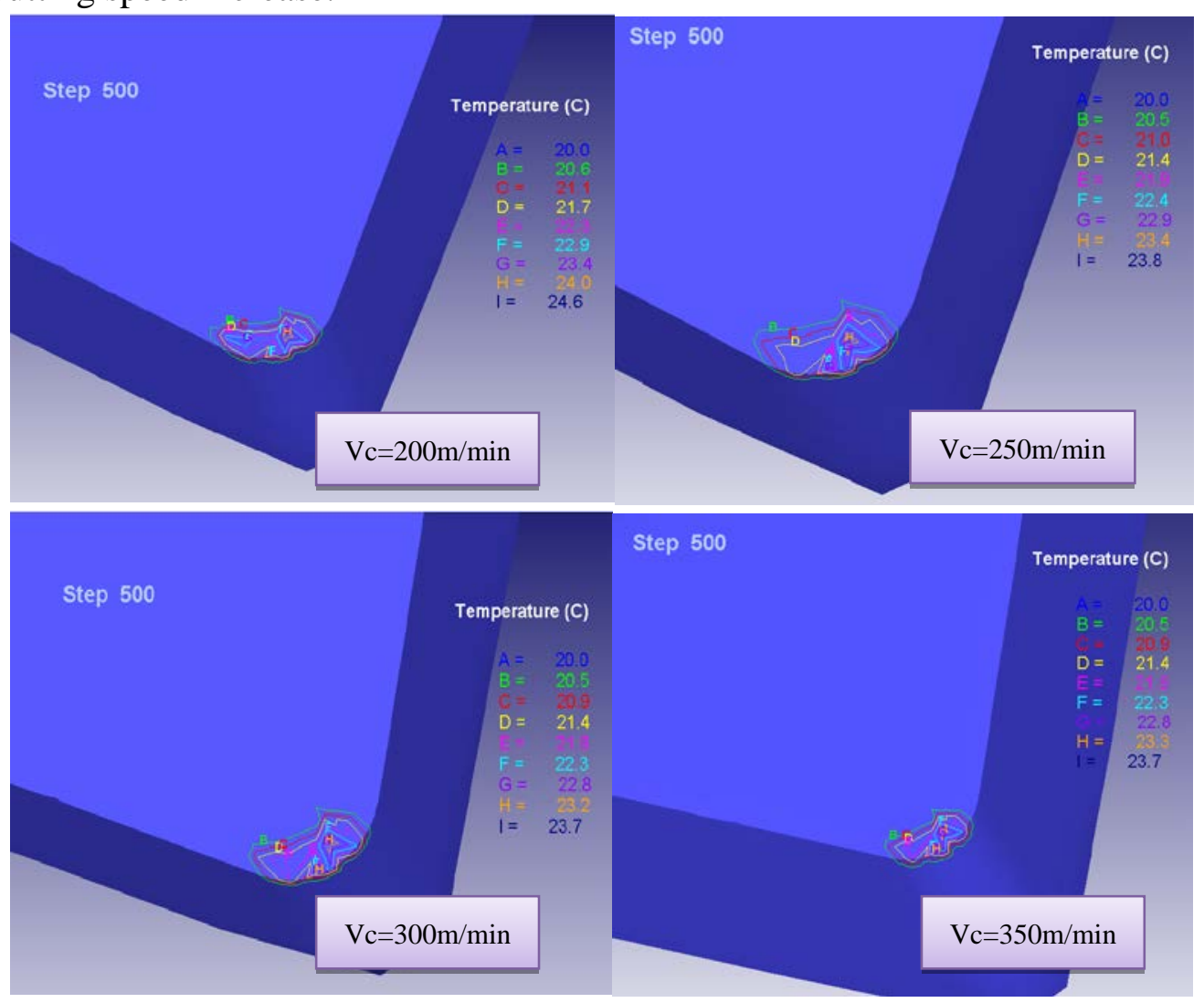

Fig.5 Temperature fields results of tool. 


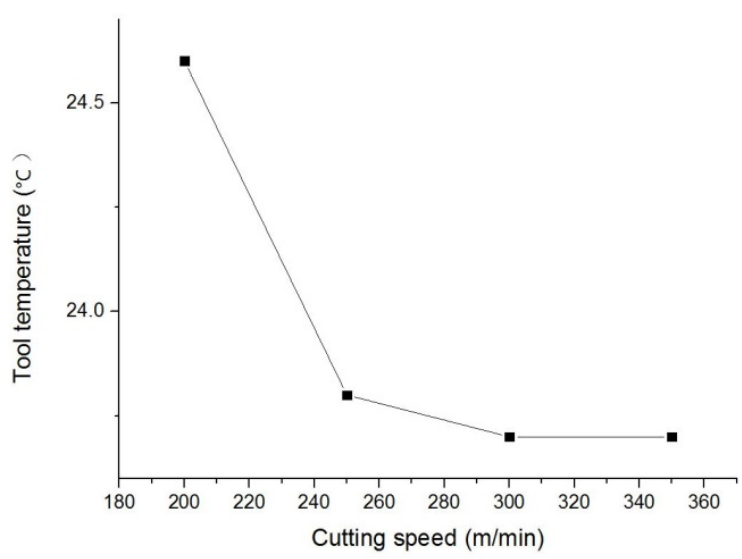

Fig.6 Relationship between tool temperature and cutting speed.

\section{Conclusions}

In this paper, the cutting HT250 process by self-prepared Si3N4 ceramic insert in different cutting speed was simulated. The simulation models were created based on the material properties of the self-prepared Si3N4 insert and HT250. It was concluded by analyzing the simulation results of cutting force, temperature field and stress field:

(1) The main cutting force was the minimum in $V_{c}=250$ or $300 \mathrm{~mm} / \mathrm{min}$.

(2) When cutting speed was beyond $250 \mathrm{~mm} / \mathrm{s}$, the tool temperature was no longer increasing.

(3) Tool stress-effective was worse at tool nose than other area, which indicated the tool nose appeared wear firstly. The stress-effective was significantly increasing in $V_{c}=350 \mathrm{~mm} / \mathrm{min}$.

(4) After analyzing cutting simulation results, the cutting properties of self-prepared Si3N4 insert were optimum in $V_{c}=250$ or $300 \mathrm{~mm} / \mathrm{min}$.

\section{Acknowledgements}

I major in the ceramic cutting tools preparation and its cutting performance. This work was financially supported by the science \& technology innovation projects in Zhuhai College of Jilin University.

\section{References}

[1] Liu Defu, Yu Xiaoxia, Lou Pingyi. Finite element analysis of temperature distribution in orthogonal metal machining [J]. Journal of Beijing Institute Technology, 1999, 8(4):386-391.

[2] Li K, Gao X L, Sutherland J W. Finite element simulation of the orthogonal metal cutting process for qualitative understanding of the effects of crater wear on the chip formation process[J]. Journal of Materials Processing Technology, 2002, 127(3):309-324.

[3] Saffar J R, Razafar M R, Zarei O, et al. Simulation of three -dimension cutting force and tool deflection in the end milling operation based on finite element method[J]. Simulation Modelling Practice Theory, 2008, 16(10): 1677-1688.

[4] Chen Wenlin, Li Wei, Liu Ning, et al. Performance of Ti (C,N)-based cermets cutter and simulation technique of cutting process[J]. International Journal of Machine Tools and Manufacture, 2008, 197(1-3):36-42.

[5] Qiang-Guo Jiang, 2016. Studies on Preparation, Microstructure and Properties of Silicon Nitride with Ternary Sintering Additives . the PhD Thesis of Guangdong University of Technology, 
p.41-61. In Chinese.

[6] Lin ZC, Lai WL, Liu CR. The study of ultra-precision machining and residual stress for NiP alloy with different cutting speeds and depth of cut. J Mater Process Technology 2000;97:200-10.

[7] Lin ZC, Lin YY. A study of oblique cutting for different low cutting speeds. J Mater Process Technology 2001;115:313-25.

[8] Outeiro JC, Umbrello D, M'Saoubi R. Experimental and numerical modeling of the residual stresses induced in orthogonal cutting of AISI 316L steel. Int $\mathrm{J}$ Mach Tools Manufacture 2006;46:1786-94

[9] Deform-user Manual 2006. SFTC-DeformV9.0.1, Scientific Forming Technologies Corporation Ed. Columbus, $\mathrm{OH}$, USA. 